\title{
A Simulation for Teaching Skills Relating to Organizational Self-renewal
}

\author{
Marjorie A. Lyles \\ Indiana University, Indianapolis, IN, USA \\ Janet P. Near \\ Indiana University, Indianapolis, IN, USA \\ Cathy A. Enz \\ Cornell University, Ithaca, NY, USA
}

The process of corporate self-renewal and the adaptation of organizations have received increased interest among executives. Strategic renewal is related to the pattern of changes undertaken in the firm's strategy and organizational processes and to the relative importance placed on these changes. It is the interface between strategy content and strategy process. The self-renewal of firms is viewed as a topic of increasing importance in strategic management because it is an essential element of a firm's ability to survive and to sustain competitiveness over time.

Yet very little attention has been directed at how to teach executives to create change within their organizations. In the last ten years most firms have faced the challenges of diversifying, down-sizing, reorienting business areas, and developing new management techniques. Managers have had few models or techniques to help them assess the process of implementing these changes.

This article is about one simulation which we have found to be helpful in teaching managers how to implement change. The function of the renewal process is to enable to firm to cope more efficiently with environmental fluctuations. In perceiving and responding to these external changes, management acts according to its own view of what deserves attention.

Such firm characteristics and constraints as resources, personalized objectives of the owners/managers, individual attitudes towards the adoptions of innovations, informal networks and power relationships indicate that the renewal process is difficult to achieve. Thus, renewal is a particularly critical element of the strategic management process and the simulation which we will describe attempts to help managers think about these issues. The name of the simulation is The Change Game.

This article addresses four major topics: 
(1) the learning objectives of the simulation;

(2) the key theoretical concepts developed in the simulation;

(3) a description of the simulation; and

(4) a discussion of some of our experiences in utilizing the simulation.

\section{Learning Objectives of the Simulation}

The primary objective of the simulation is to teach students about the process of planned organizational change using an experiential base. The simulation has been used successfully with various types of learners, including undergraduates, MBA students and practicing executives and managers.

The use of this experiential exercise provides several benefits. It allows participants to consider a particular case of change experienced by everyone in the group. It permits students to try out their personal theories about change and to learn from doing. It portrays the sociopolitical aspects of organizations and the impact these have on change efforts. It helps students to understand the frustrations change agents experience while overcoming resistance to change.

The learning process is inductive. Participants try various strategies to effect change, and by keeping a record of successes and failures they derive general principles about which strategies work well and which are less effective. The simulation seems to aid learning in that students become highly involved in the process. As a result they should learn the information better and retain it for a longer period of time.

In conclusion, the objectives of the simulation are:

(1) to describe the stages of adoption of innovation: awareness, appraisal/trail and adoption;

(2) to define individual differences in terms of their reaction to organizational change and innovation: innovators, early adopters, early majority, late majority and resisters; and

(3) to apply appropriate tactics and strategies which reflect the different stages of adoption of innovation and individual differences in reaction to change.

The simulation is based on several theoretical concepts about organizational change. The diffusion of innovation literature serves as a basis for introducing the stages of diffusion and types of adopters. The importance of networks and of the social and political relationships among the people in the organization are presented as important in influencing individuals to adopt change. After playing the simulation, the participant should recognize that opinion leadership is not dependent on formal authority status but it is a crucial channel of influence.

Techniques and skills for introducing change are presented in the simulation through the alternative options which the participants have. Tied to these is the recognition that various diffusion activities are more effective in different phases of the adoption process. The importance of the role of top management in the renewal process in firms is incorporated into 
the simulation. Last but certainly not least, an important concept is luck. The simulation creates different responses to techniques used at different points of time. It offers a view that creating change is part skill, part art, and part luck.

\section{Description of the Simulation}

The simulation is designed to be played in two hours. This time may be split into two sessions of one hour each. Although two hours probably represents the minimum time required, the game could easily consume a three- or four-hour block including the processing of the simulation after playing it is over.

The participants, organized into three-person teams, play the role of a consultant team hired by the corporate headquarters to implement a specified change in the Northwest Division of a company. The consultant team has a period of two years to persuade the organization members to adopt a management-by-objectives (MBO) programme. The objectives of the team are to persuade as many of the staff members as possible to adopt $\mathrm{MBO}$ and to maintain a climate receptive to future innovations.

The number of persons who may play at one time is highly flexible, ranging from one person to as large a group as the facilities will accommodate. It has been played with a class of 100 students. The total group should be divided into consultant teams of three or fewer persons per team. Teams larger than three tend to play too slowly.

Consultant teams are grouped in clusters of three teams with a facilitator. The facilitator provides each team with information requested during the rounds of play and the feedback about the effectiveness of the actions taken by the teams. Typically one facilitator will manage the play of three teams. The training of the facilitator takes about 30 minutes.

The progression through a two-year period is marked by a series of rounds or turns. During each round the team implements one of 17 change tactics or strategies available (Appendix I). Each tactic used for a given round of play costs the consultant team one or more week(s) of time from their two-year time allocation. The team is given feedback about the effectiveness of their move. The feedback tells the team the total cost in weeks of the move, an explanation of what happened, and the number of points they get towards the adoption of the member of the firm. The teams also have the options of receiving background information about each of the members of the firms, the committee structure, lunchmate preferences and social patterns (Appendix II).

The simulation can end for a given team in one of three ways: all members of management have become adopters; the two-year period of time is up; or the consulting team is asked to leave the organization because they chose to use tactics which angered the upper management. Experience with the game has shown that usually the instructor stops the game because the class time is used up before the total number of adopters is secured or before the two- year allocation is used. 
Following the end of play of the simulation, the facilitator begins to process the experiences of the teams. The teams are asked to evaluate how they made decisions about introducing the innovation, whether they had a strategy for change, and what seemed to be the important aspects of change. The participants are also presented with the theoretical underpinnings of the simulation. The teams often identify for each other the importance of the role of upper management for championing the change, the difficulty of mandating change and the importance of creating a social context for change. The reality that some parts of the firm will be resistant to change, and that the manager needs to know how best to address this, is apparent. The processing of the simulation typically takes a minimum of 45 minutes, but can also involve much longer in-depth analysis as each team gets back together to discuss their decision-making styles, the strategies they employed and the learning which occurred.

\section{Learning Outcomes}

The simulation provides a list of change strategies (see Appendix I) which can be used to introduce change. The participants discover during the game that some strategies are more successful in different stages of the change process. For example, obtaining background information on an employee or setting up a meeting and informally interviewing a manager are useful tactics during the awareness stage of adoption for that manager. During awareness, organizational participants are becoming alerted to the existence of the intervention. Thus these strategies will result in the game-player accruing more points and greater success. Continuing to employ tactics which are useful in the awareness stage in a later phase of the change game, however, could become frustrating and ineffective for the players. In the appraisal or trial stage, for example, the objectives are to strengthen the idea of the innovation and to allow the organization to apply it to a particular situation. Using a strategy such as interviewing would be less effective during this stage than pilot tests which ask a particular individual to implement a short-term project. Hence, one of the primary objectives of the game is to teach the game-players that organizational change tactics correspond to different stages of readiness or willingness to accept change.

An additional learning outcome of the game is teaching players that various individuals will respond to the same change at differing paces. Some of the game s managers have been identified as innovators. They are daring and imaginative and quick to try new ideas. For these organizational members, the game-players discover that they can quickly move them through the stages to adoption. Other organizational members may be early adopters, the earlier majority, the late majority or resisters. The latter category are the hardest to convince to become adopters and frequently will adopt only after 95 per cent of the firm members have adopted.

Particular characters in the game who are resisters distrust and reject any attempt to introduce innovation and cause the game-players to experience frustration and annoyance. If the game-players focus only on the group of adopters who are innovators or only on the group who are resisters, they will not succeed in the game. Hence an additional learning outcome of 
the game is an appreciation of trying multiple tactics with different individuals at different stages in the change process. The combination of stages of adoption, strategies for intervention and differing levels of resistance are all combined in the game to show the player the dynamics and the complexity of organizational implementation of change.

A final learning outcome of the game is the opportunity for participants to understand the frustrations and successes of introducing change. Early on, the participants will experience frustration because their attempts to introduce interventions will be slow and will be met with resistance. Teams of players may experience disagreement and frustration in their group. These experiences are designed into the game so that the players come to appreciate both the slow pace of change and the frustrations involved in trying to implement change.

Frequently, players become more successful with introducing change after about an hour to an hour-and-a-half of playing the game. Once they experience success, the group dynamics within a playing team improves. If success is not experienced, decision making breaks down and individuals become more frustrated; rather than thinking through the game, they begin to grab at straws, taking risks and losing large points as well as aggravating themselves and others in their group.

The ability of a group of individuals to become caught up in the introduction of change results in an unawareness of group dynamics until later. This particular experience of intense involvement allows the group to later explore their own assumptions about change and their own willingness as a group to cope with frustration as well as success. The next section will discuss some of the experiences we have had running the game.

\section{Experience in Running the Game}

Over the years, we have conducted the game with a variety of different groups in several different course contexts. We have used the game with undergraduate students, MBAs, executive education participants and business school educators. In addition, we have employed the game in courses on organizational design and theory, organizational change and development, and strategic management. It has been used in the United States and in Europe.

To maximize the use of the game, we have frequently attempted to conduct it in two separate time-periods in which group participants have a chance to communicate with each other informally, discuss in groups or spend more time thinking about what transpired in the first session before beginning the last session of play. This fits well into a twice-a-week class schedule.

Introducing a relatively long gap between playing the game in its first rounds and playing the game in its last rounds evokes a remarkable difference in attitude and team ability. We believe that players who spend time trying to figure out together why they are failing (e.g., no adopters), begin to piece together the linkages or the cues between stages of adoption, strategies for adoption and individual differences. Often, we have found managers who return 
to play the game may have a strategy or game plan. Most often (but not always), the preparation between the first and the second rounds of play improves the performance of the game-players. We have come to believe that this is because of the opportunity to reflect on the experience. While busy playing the game, the players often forget to think through their prior mistakes. Een though the players keep a log of all their decisions and outcomes, they rarely use this information to improve on their future decisions unless they are given some time to sit back and think through the process. We believe that one of the advantages of breaking up the game into two separate sessions is to allow respondents to think for some period of time about what they have done correctly and incorrectly.

It has been our experience that when the game begins, older and more mature players take a great deal of time to orient themselves to the game. They are frequently very slow to begin actually taking turns, and they try to come up with a grand plan or strategy before they begin the game. Because of their hesitancy to make a mistake, many players need to be prodded into beginning the game. Once they begin the game, the first two or three decisions about what tactics to employ shape group dynamics and become critical for the success of a team.

If a particular team attempts to contact the most senior manager in the game without collecting information or working through a secretary, they become frustrated at their lack of success. At this point it is an automatic response of many players to suggest that the game is unrealistic or inappropriate and that they do not understand why they cannot see the person in charge. They do not appreciate the fact that the secretary serves as a gatekeeper. It is not until we debrief the game that we remind the participants that organizations are political and that some of their frustration is the result of the political dynamics and their insensitivities to these dynamics. We have also experienced that some of the teams who get frustrated with the slowness of the process will sometimes opt for the most risky strategies.

Once respondents begin to play and have success, there is a tendency for them to continue doing what works rather than shifting gears and exploring. Very often an initially successful group starts to lag behind because of its unwillingness to try new or different tactics after moving past the preliminary stages of awareness and interest. We find this aspect of the game to be a common and consistent trap whether undergraduates, MBAs or executive education participants are playing the game.

Much to our surprise, we have found that often the mistakes which our undergraduates make in playing the game are also the mistakes made by more "seasoned" managers. After about an hour and a half of game-play, the game is usually stopped. At this point, many respondents will have no adopters yet, will be very frustrated and quite unhappy with us as facilitators. The emotional response of managers has often been that the game is unrealistic, it is too frustrating, that they are not successful in introducing change. They argue that if they had complete control they would change the rules of the game. We frequently seize this opportunity to remind them that the rules of many organizational games are beyond our 
control to change. We ask them to go away with some ideas for how to create more proactive strategies and to diagnose the data they already possess on what is succeeding and what is failing and why.

When our executive education managers return from reflection on the first rounds of play in the game, they are usually ready to jump into the game with vigour. Very often we find that the frustration has increased their commitment and investment in "winning" the game. The more successful they are, the more rapid play becomes and soon the facilitators have a difficult time keeping up with the participants who are constantly trying to introduce new strategies.

Close to the end of the game, different teams begin to compete with each other to quickly and effectively get as many adopters as they possibly can before the time runs out. Frustration is usually gone by this point and game-players have figured out key components of the framework behind the game. It is only the most unsuccessful teams which still have not come to understand the importance of changing their tactics for different stages and different individuals in the game.

It has been our experience that a lively discussion can frequently follow the playing of the game. In addition to talking about resistance to change, stages in the change process and a variety of other conceptual models of change, we very often have to discuss issues about decision making in groups and the role of emotion and politics in coming to understand change. While we would readily agree that the game has its own constraints and may have moments of being unrealistic, we have also found over time that the more experience our players have had trying to introduce change in their own organizations, the more realistic they find the game to be. The game is premissed on the feet that change is slow, that individuals resist, and that those who need to be changed are not the ones who have been asked to introduce the change.

A variety of modifications to the game can be made. One of the authors, for example, has modified the game such that it focuses exclusively on surface industries, in particular the lodging industry. Another modification of the game would be to change the content of the intervention suggested. While the game was designed to look at MBO, it can easily be modified to address issues of quality assurance or a host of other types of interventions which may be more germane in the 1990s.

One variation is to change the monetary structure of the game so that the cost in terms of weeks comes at a cost of real dollars to the players, hence changing their motivation and level of commitment. One final variation which has been employed with interesting results is to provide a competitive tone to the game by comparing the participants with others in their corporation or MBAs at other institutions. One of the authors recently used the simulation with MBAs at Harvard University and inspired them by informing them that their success in the simulation to date had not been as great as that of MBAs in other institutions in which the 
game had been played. This incentive alone seemed to elicit a great deal more involvement and commitment to show the professors that the game could be played better than by others.

While the primary focus of the simulation is to discuss change and change issues, it has evoked a variety of broad-reaching discussions. Topics which are peripheral to the game but often emerge involve group dynamics, groupthink, emotion and frustration in organizations, the political context in which change and decisions are made and even questions of organizational design and redesign to improve the implementation of change.

At the conclusion of the simulation with a group of undergraduates at Cornell, recently, one of the authors asked the students to appraise the realism of the game. The students promptly responded that while the game helped them to understand organizational change, it was not realistic. At that point the students were introduced to a real consulting project in which they became consultants to a luxury hotel. While spending the rest of the semester serving as consultants to the organization, the students not only discovered the complexities of change but also came back to reappraise the game as far more realistic than they had imagined. In this instance, it appeared that the viability of the organizational change game grew when the participants attempted to introduce change in real organizations.

We believe this may suggest that one of the strengths of the organizational change simulation is that for those who have experienced organization changes and attempted to introduce change in organizations, the game has tremendous salience and relevance. Those who have yet to experience change discover that the game, while being a simulation, is also a realistic mapping of the difficulties and opportunities involved in introducing change but without the accompanying costs of doing it in their own organization.

\section{Creating Skills for the Self-Renewal of Firms}

Planning for self-renewal is a constant need for every firm. The need for organizations to be flexible, to embrace change, to tolerate ambiguity and complexity, and to be innovative will be the challenge of the future. As we have seen in the last few years, the old models of stability, standard operating procedures and maintaining the status quo are not going to be the models of the future. The current economic and political environments have led to greater change in organizations than we have ever seen in the past. They have led to large-scale organizational restructuring and manpower changes in very short time-periods.

The institutionalization of change is a need that organizations will have in the future. The importance and persistence of change advocacy will be a major agenda item. The role of the change agent will be the responsibility of every manager. Each manager will be responsible for creating the process of self-renewal and of continuity and change will move the organization towards the future.

The simulation which we have described can help managers to prepare for this critically important role. It helps to develop skills in creating change as well as providing important 
insights into the change process. The simulation provides the managers with a set of skills which they can use to assess then- own effectiveness in creating change and in evaluating the readiness of then- firms for change.

\section{Appendix I: Change Tactics and Strategies}

Ask help: Ask any one of the staff for advice or help in one of your OD strategies.

Background: Obtain background information on any three employees.

Committees: Find out who are members of the various committees set up in the division.

Company newsletter: Arrange to have a brief article in the company newsletter/magazine about MBO at the Northwest Division.

Compulsion: Persuade the V-P to issue a bulletin directing all directors and managers to institute MBO immediately.

Confrontation: Work behind the scenes with a group of managers who want to take some action to improve productivity in the division. At your suggestion, they meet the $\mathrm{V}-\mathrm{P}$ to lobby for the use of MBO as one method for improving productivity.

Executive development: Arrange for any five employees to attend an executive development programme on MBO. Specify the five.

Interdepartmental unit meeting: Arrange for several directors/managers to meet and discuss MBO.

Internal workshop: Have a particular manager/director lead a session on creative issues of MBO.

Interview: Set up a meeting and informally interview one person.

Lunchmates: Observe who lunches with whom.

Memo: Send a brief report describing the advantages of MBO to any five persons. Specify the five.

Pilot test: Attempt to influence one director/manager by asking him/her to let you implement $\mathrm{MBO}$ in a short-term project.

Presentation: Get on the agenda of a regularly scheduled staff meeting to explain MBO and encourage discussion about it.

Sample survey: Send a survey to several directors/managers to gather information about interest in setting up an MBO programme.

Seminar: Arrange to invite Professor Peter Drucker to speak on "MBO: Its Role in Increasing Productivity". 
Social: Observe the social patterns to learn who plays golf, racket ball, etc. together.

\section{Appendix II. Example Information Requests}

Information about Lunchmates

(1) Comptroller and secretary

(2) Research, product development, and OD

(3) Marketing, personnel, marketing research, and employee relations

(4) V-P, production, R\&D, liaison to production, and industrial relations

(5) Finance, plant $\mathrm{C}$ manager, sales, budget and planning, purchasing and accounting.

Background Information about Vice-President

Very ambitious (has a 20-year plan), active member of the Rotary Club and local Republican Club, delegates authority to able subordinates but runs a "tight ship". Has a MBA from a prestigious Eastern university. 